\title{
Creativity in Mathematics Education
}

\author{
Hartwig Meissner
}

\section{Report}

The Discussion Group 2 on Creativity in Mathematics Education at ICME-12 in Seoul, affiliated with MCG, was a great success. Co-chaired by Board members Emily Velikova and Vince Matsko, the group focused on issues relating to creativity in the classroom as well as training both pre-service and in-service teachers regarding effective ways of fostering creativity.

DG 2 faced difficulties in communicating with ICME organizers, and as a result, participants were not able to see the proposals before the conference. As a result, the chairs decided to begin each of the two ninety-minute sessions with brief summaries of the papers delivered by their authors. These were both lively and informative, and gave the $100+$ participants in DG 2 a chance to be brought up to speed.

The sessions focused on the following questions, developed by the Board earlier in the year:

- What does creativity mean in the process of teaching and learning mathematics?

- How can we develop or stimulate creative activities in and beyond the mathematics classroom?

- How might we balance mathematical skill training and mathematical creativity?

- What should be done in teacher training programs at the pre-service and inservice levels to foster creativity in the classroom?

Organizers Chair: Hartwig Meissner (Germany); Team Members: Emiliya Velkova (Bulgaria), Jong Sul Choi (Korea), Vince Matsco (USA), Mark Applebaum (Israel), Ban Har Ywap (Singapore); Liaison IPC Member: Bernard Hodgson (Canada).

H. Meissner $(\bowtie)$

University of Münster, Münster, Germany

e-mail: meissner@uni-muenster.de

(C) The Author(s) 2015

S.J. Cho (ed.), The Proceedings of the 12th International Congress

on Mathematical Education, DOI 10.1007/978-3-319-12688-3_64 
(Note: a link to the DG 2 website, including a full description of the Discussion Group as well as all the submitted papers, is accessible from the MCG website.)

The first session addressed the first two questions, while the second centered around the last two. The chairs subdivided the first two questions into six, so that smaller discussion groups could be formed. DG 2 participants selected the question they wished to discuss, and elected a representative who summarized the discussion at the end of the session. Many participants remarked on quality of the discussions, and all were stimulated by the sharing of ideas.

The second session was rather smaller than the first, occurring on the last full day of ICME-12. As a result participants voted to have a large group discussion rather than breaking into smaller groups. This proved to be effective-and even though participants were tired after a hectic week, it proved difficult to make sure everyone had a chance to speak. Those involved had a real passion for creating engaging activities in the mathematics classroom, and there was no shortage of ideas to share.

Of course, in discussions like these, more questions are raised than are answered. These questions came up as a response to concerned teachers truly wanting to be more creative in the classroom. Among the questions raised by the DG 2 participants were:

- How do we decrease pressure on students so that they are more free to be motivated and involved in mathematics?

- How can we use technology to allow students to demonstrate originality, flexibility, and fluency of thought?

- How can we develop creativity within a pre-service teacher's university experience?

- Given we believe that all students can be creative, how can we create opportunities for students to do so?

- How can we deliberately foster creative thinking to encourage innovation?

- How can we provide accessible resources for teachers so that they may more easily bring creative activities into their classrooms?

- How can we change the climate of university education departments so that developing creativity in teachers is valued and addressed in the curriculum?

- How can creativity in mathematics education be made a priority at a regional or national level?

Of course none of these questions has an easy answer. But one or more of them might be suitable for a discussion forum or a special session of a conference on education. We welcome contributions to this newsletter from mathematics educators who have successfully answered one of these questions either in their classroom, or who made an impact regarding one of these questions on a local, regional, or national level.

Open Access This chapter is distributed under the terms of the Creative Commons Attribution Noncommercial License, which permits any noncommercial use, distribution, and reproduction in any medium, provided the original author(s) and source are credited. 